\title{
On the Relationship Between Lifestyles and Obesity in Adult Working Women in Dhaka
}

\author{
Khadija Begum ${ }^{1, *}$, Mohammad Shariful Islam ${ }^{2}$, Mohammad Nurul Anowar ${ }^{2}$ and Won Hee Lee ${ }^{3}$ \\ ${ }^{1}$ Mugda Medical College and Hospital, Dhaka, Bangladesh \\ ${ }^{2}$ Department of Adult and Elderly Health Nursing, National Institute of Advanced Nursing Education and Research, Dhaka, Bangladesh \\ ${ }^{3}$ National Institute of Advanced Nursing Education and Research, Dhaka, Bangladesh \\ "Corresponding author: Senior Staff Nurse, Mugda Medical College and Hospital, Dhaka, Bangladesh. Email: khadijaminirafim@gmail.com
}

Received 2019 October 22; Revised 2019 December 14; Accepted 2019 December 23.

\begin{abstract}
Background: Obesity has been considered as a major public health problem across the globe, and Bangladesh is not an exception in this regard.

Objectives: The present study aimed to investigate the relationship between lifestyles and obesity among adult working women in Dhaka.

Methods: This cross-sectional study was carried out using face-to-face interviews from January 2017 to June 2018 . In this study, 226 working women from a public hospital and a public bank were selected using convenient sampling and then interviewed. The relationship between lifestyles and obesity was examined using pretested semi-structured questionnaire. The collected data were analyzed by SPSS software version 23 using chi-square $\left(\chi^{2}\right)$, paired-sample $t$-test, and one-way ANOVA tests.

Results: The mean age of the participants was $37.35 \pm 6.80$ years, ranging from 23 - 55 years. About $44 \%$ were overweight and $16.0 \%$ were obese. Older age $(P=0.02)$, marriage $(P=0.01)$, greater number of children $(P=0.01)$, and more income $(P=0.01)$ were significantly associated with obesity. The participants who skip their breakfast three or more times and skip their main meal one to two times or more in a week showed higher BMI, which was statistically significant.

Conclusions: Marriage, aging, more affluence, and less physical exercise were found as major risk factors for obesity. The findings of this study can provide the appropriate ground for monitoring the effectiveness of national programs in order to prevent and control obesity in Bangladesh, especially among women.
\end{abstract}

Keywords: Obesity, Working Women, Risk Factors, Bangladesh

\section{Background}

Obesity has been considered as a global major public health problem resulting from imbalance between calorie consumption and expenditure (1). According to World Health Organization (WHO), about 1.9 billion adults were overweight and 650 million adults were obese worldwide in 2016 (2). Obesity adversely affects women's health and is considered as the fifth leading cause of death in the world (3). Globally, about 300,000 persons die from obesity annually (4). It is the major cause of non-communicable chronic diseases in women, including metabolic syndrome, diabetes mellitus, hypertension, dyslipidemia, coronary heart disease, stroke, anxiety, and depression throughout the world $(5,6)$. It imposes an unusual economic burden on families, society, as well as the nation. In 2006, it accounted for $1.2 \%$ of gross domestic product expenditure in the US and 2.74 billion US dollars in China (6).

Lifestyle (i.e., dietary habits, physical inactivity and sedentary life style) is a factor contributing to obesity among adult working women (7). Globally, there has been an increasing intake of energy-dense foods and increasing urbanization followed by decreased physical activity, leading to a sedentary life and consequently obesity $(4,6)$. The universal use of information technology includes the use of computers. In this regard, extra use of social media reduces the physical activity both at home and workplace (4). Major dietary changes encompass the intake of high energy diet, fat, added sugar in foods, increased food from animal sources, decreased intake of dietary fiber, and reduced intake of fruits and vegetables and contribute to developing obesity $(6,8)$. Sedentary behavior and patterns of physical inactivity are effective factors to develop obesity at such an epidemic level in both developed and developing countries $(9,10)$. Energy imbalance, though, was from the 
result of adopting a more sedentary lifestyle with no equivalent reduction of energy intake and physical exercise in the developing world, especially among women $(11,12)$.

Like other parts of the world, obesity is a rising public health concern in Bangladesh; however, it has been less investigated. Accordingly, there is a dearth of research exploring the risk factors and preventive strategies for this ever-burdening problem. The prevalence of obesity among adult women was reported to be 2.5 times higher in urban areas than rural ones, increasing the overweight/obesity trends in Bangladesh $(5,13)$. This would be beneficial for the stakeholders if the risk factors of obesity are detected. This information would help to provide interventions, health educations, and, in general, to prevent the obesity. The dietary habit and lifestyle interventions aimed at decreasing energy intake and increasing energy expenditure through a balanced dietary and exercise program. These two factors are an essential component of all weight management programs and complementary to clinical preventive strategies.

\section{Objectives}

To this end, the present study aimed to investigate the relationship between lifestyles and obesity among adult working women in Dhaka.

\section{Methods}

\subsection{Design and Participants}

This descriptive cross-sectional study was conducted in NIANER from January 2017 to June 2018. The data were collected from 226 working women from a public hospital (140) and public bank (86) in Dhaka. The participants were selected using convenient sampling technique, and the data was extracted from face to face interviews along with semi structured questionnaires. Women aged 20 59 years and living in Dhaka for the last one year were included, and pregnant and post-partum women and lactating mothers were excluded from the study.

\subsection{Research Instruments}

An interview and questionnaires were used to collect data. A 36-item structured questionnaire was developed by the research team to address lifestyles and obesity. This instrument was divided into 4 sections: (1) socio-demographic questionnaire (SDQ) with 14 items, (2) dietary habits assessment questionnaire (DHAQ) with 13 items, (3) physical activity questionnaire (PAQ) with 5 items, and (4) sedentary behavior questionnaire (SBQ) with 4 items. The Body Mass Index (BMI) [( $\mathrm{kg}) /$ height $\left.\left(\mathrm{m}^{2}\right)\right]$ was used to calculate the obesity.

\subsubsection{Part-I: Socio-Demographic Questionnaires}

The SDQs consists of 14 items addressing age, height, weight, religion, level of education, marital status, number of children, type of family (nuclear or extended), occupation/designation, monthly family income, housework assistant, taking contraceptive pills, and unhealthy habits of the respondents.

\subsubsection{Part-II: Dietary Habits Assessment Questionnaires}

A 13-item DHAQs with a five-point scoring scale (0 - 4) was used to measure the variables such as skipping breakfast, skipping main meal, and eating meat, eggs, fruits, fast foods/fried foods, tea/coffee, extra salts /salty foods, ice-cream/sweets, vegetables, soft drinks/carbonated beverages, meals with family (homemade food), and outside meals consumed over the last seven days.

\subsubsection{Part-III: Physical Activity Questionnaire}

Physical activity status was examined using five items with a five-point scoring scale $(0-4)$ to find out some information about walking/exercise time, time spent for house work, cycling, swimming, and walking to office or time spent in a typical day. The higher scores indicated more physical activities.

\subsubsection{Part-IV: Sedentary Behavior Questionnaire}

The sedentary behavior of the women was measured by 4 items with a five-point scoring scale $(0-4)$. These items provided information about the amount of time spent or prolonged sitting in a typical day such as watching TV and taking snacks, reading, using computer, using social media (Facebook, YouTube, Instagram, WhatsApp, etc.). The higher scores indicated more sedentary behavior among adult working women.

\subsection{Validity of the Instruments}

The content validity of the instruments was determined by three experts (two from NIANER faculty and a Korean expert from the College of Nursing, Yonsei University, South Korea). The experts were asked to assess the relevance and clarity of the instruments with regard to their construct in Bangladeshi culture. The expert team evaluated the content validity of the instruments to find out whether they were sufficiently relevant and whether they adequately measured the study variables.

\subsection{Obesity Assessment by Anthropometric Measurements}

The weight and heights of the women were measured by the researcher. The anthropometric measurement of height and the weight was recorded in kilogram $(\mathrm{kg})$ keeping the participants standing motionless on a portable 
weighing scale. Their height was measured in cm using a measuring tape for the participants standing in the erect position. The measurement procedure and findings were recorded carefully by the researcher. The BMI was calculated using the equation BMI $\left(\mathrm{kg} / \mathrm{m}^{2}\right)=$ Weight $(\mathrm{kg}) /$ Height $\left(\mathrm{m}^{2}\right)$. Regarding the criterion for obesity among the adult population proposed by WHO, the cut-off points were categorized into four groups as underweight $(<18.5)$, normal bodyweight (18.5 - 24.9), overweight (25.00 - 29.9), and obese $\geq 30.00 \mathrm{~kg} / \mathrm{m}^{2}(2)$.

\subsection{Data Analysis}

The data were analyzed using SPSS software version 23.0. Before analyzing the data, all data were checked and rechecked to ensure the accuracy of the data entry. Descriptive statistics such as frequencies, percentages, mean, and standard deviation were used to describe the participants' individual characteristics, dietary habits, physical activity, and sedentary behaviors. The relationship between lifestyles and BMI was tested using chi-square $\left(\chi^{2}\right)$, pairedsample $t$-test, one-way ANOVA, and Pearson's correlation to determine statistically significant relationships. In this study, $\mathrm{P}<0.05$ was set as the significance level.

\section{Results}

The mean age of the participants was 37.35 years $(\mathrm{SD}=$ $6.80)$, ranging from 23 - 55 years; a majority of the participants (51.3\%) belonged to the age group of 30 - 39 years; $74.8 \%$ were Muslim, and 92.8\% were married (Table 1). Most of the participants (81.4\%) took no contraceptive pill. The mean BMI was $26.31 \mathrm{~kg} / \mathrm{m}^{2}$ (SD = 3.38), ranging from 17.97 to 35.26 . In this regard, $44.2 \%$ were overweight, and $16.0 \%$ were obese (Figure 1).

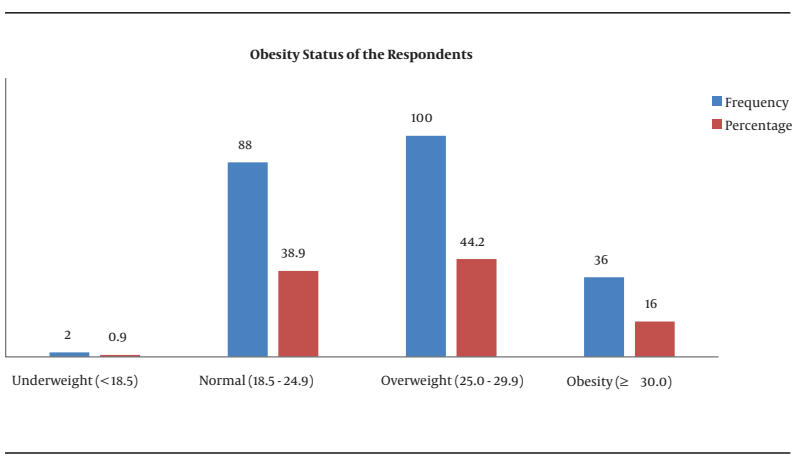

Figure 1. Distribution of obesity status among respondents $(n=226)$

The obesity had a significant relationship with age ( $P$ $=0.02)$, marital status $(\mathrm{P}=0.01)$, number of children $(\mathrm{P}=$

\begin{tabular}{|c|c|}
\hline Variable & Values $^{\mathrm{a}}$ \\
\hline Age, $y$ & $37.35 \pm 6.80$ \\
\hline$<30$ & $33(14.6)$ \\
\hline $30-39$ & $116(51.3)$ \\
\hline $40-49$ & $69(30.5)$ \\
\hline$\geq 50$ & $08(3.5)$ \\
\hline \multicolumn{2}{|l|}{ Religion } \\
\hline Muslim & $169(74.8)$ \\
\hline Non-Muslim & $57(25.2)$ \\
\hline \multicolumn{2}{|l|}{ Level of education } \\
\hline Primary & $18(8.0)$ \\
\hline Secondary & $44(19.4)$ \\
\hline Tertiary & $164(72.6)$ \\
\hline \multicolumn{2}{|l|}{ Marital status } \\
\hline Single & $17(7.5)$ \\
\hline Married & $209(92.5)$ \\
\hline \multicolumn{2}{|l|}{ Number of children } \\
\hline No children & $27(11.9)$ \\
\hline 1- 2 children & $154(68.1)$ \\
\hline 3 - 5 children & $45(19.9)$ \\
\hline \multicolumn{2}{|l|}{ Settings } \\
\hline Hospital & $140(61.9)$ \\
\hline Bank & $86(38.1)$ \\
\hline Family income, BDT & $108362.57 \pm 50579.84$ \\
\hline$<108362.57$ & $120(53.1)$ \\
\hline$\geq 108362.57$ & $106(46.9)$ \\
\hline \multicolumn{2}{|l|}{ Living status } \\
\hline Alone & $18(8.0)$ \\
\hline Single family & $169(74.8)$ \\
\hline Joint family & $39(17.3)$ \\
\hline Sleeping hours & $6.38 \pm 1.68$ \\
\hline$<6$ & $79(35.0)$ \\
\hline $6-8$ & $111(49.1)$ \\
\hline$>8$ & $36(15.9)$ \\
\hline \multicolumn{2}{|l|}{ Housework assistant } \\
\hline No & $141(62.4)$ \\
\hline Yes & $83(37.6)$ \\
\hline \multicolumn{2}{|l|}{ Contraceptive pill } \\
\hline Never used & $184(81.4)$ \\
\hline Formerly or currently used & $42(18.6)$ \\
\hline
\end{tabular}

$0.01)$, occupation $(\mathrm{P}=0.01)$, monthly income $(\mathrm{P}=0.01)$, family type or living status $(\mathrm{P}=0.02)$, housework assistant $(\mathrm{P}=$ 0.01 ), and contraceptive pill $(\mathrm{P}=0.01)$ (Table 2$)$.

The participants who skipped their breakfast three or more times showed a higher BMI, which was statistically significant in comparison to the other individuals. Women who skipped main meal once, twice, or more per week were more exposed to the risk of obesity. Taking fast foods and regular meals with family members were signif- 


\begin{tabular}{|c|c|c|c|}
\hline Variables & Mean \pm SD & $t$-test $/ \mathbf{F}$ & PValue \\
\hline Age & & -2.31 & 0.02 \\
\hline$<37$ years & $25.84 \pm 3.65$ & & \\
\hline$\geq 37$ years & $26.85 \pm 2.91$ & & \\
\hline Religion & & 0.445 & 0.66 \\
\hline Muslim & $26.37 \pm 3.41$ & & \\
\hline Non-Muslim & $26.14 \pm 3.23$ & & \\
\hline Level of education & & 0.263 & 0.77 \\
\hline Primary & $26.85 \pm 3.06$ & & \\
\hline Secondary & $26.34 \pm 3.47$ & & \\
\hline Tertiary & $26.24 \pm 3.37$ & & \\
\hline Marital status & & 3.009 & 0.01 \\
\hline Single & $23.99 \pm 3.77$ & & \\
\hline Married & $26.50 \pm 3.26$ & & \\
\hline Number of children & & 5.833 & 0.01 \\
\hline No children & $24.59 \pm 3.98$ & & \\
\hline 1- 2 children & $26.31 \pm 3.22$ & & \\
\hline $3-5$ children & $27.33 \pm 3.05$ & & \\
\hline Setting & & 2.543 & 0.01 \\
\hline Bank & $27.02 \pm 3.43$ & & \\
\hline Hospital & $25.87 \pm 3.24$ & & \\
\hline Monthly income in taka & & -2.610 & 0.01 \\
\hline$<108362.57$ & $25.77 \pm 3.45$ & & \\
\hline$\geq 108362.57$ & $26.92 \pm 3.15$ & & \\
\hline Living status & & 3.920 & 0.02 \\
\hline Alone & $24.36 \pm 3.99$ & & \\
\hline Single family & $26.37 \pm 3.14$ & & \\
\hline Joint family & $26.97 \pm 3.71$ & & \\
\hline Sleeping hours & & 1.253 & 0.29 \\
\hline 4 - 5 hours/day & $26.77 \pm 3.47$ & & \\
\hline $6-8$ hours/day & $26.14 \pm 3.40$ & & \\
\hline$\geq 9$ hours/day & $25.82 \pm 2.92$ & & \\
\hline Housework assistant & & -2.736 & 0.01 \\
\hline No & $25.86 \pm 3.51$ & & \\
\hline Yes & $27.06 \pm 2.96$ & & \\
\hline Contraceptive pill & & -2.847 & 0.01 \\
\hline Never used & $25.99 \pm 3.29$ & & \\
\hline Used (current/prev.) & $27.55 \pm 3.37$ & & \\
\hline
\end{tabular}

icantly associated with obesity (Table 3). Performing manual housework activities more than 2 hours per day was re- ported by 53.1\%, and the rest of the participants either did not perform housework or performed such activities less than two hours, which had a statistically significant relationship with higher BMI $(\mathrm{P}=0.018)$ (Table 4).

\section{Discussion}

This study aimed to investigate the relationship between lifestyles and obesity among adult working women in Dhaka. In this study, 226 working women from a public bank and a public hospital were interviewed. The study revealed that aging was significantly correlated with obesity $(\mathrm{P}=0.02)$. In addition, the marital status, high economic status, number of children, occupation, housework assistant and contraceptive pill were also significantly correlated with overweight/obesity in the present study. This finding is similar to the findings of previous studies conducted in India, Malaysia and Bangladesh, indicating that living in urban area, participants' middle age, high economic status, marital status, monthly income, occupation were more likely to be significantly associated with obesity among women $(5,12)$.

The present study revealed that skipping breakfast three or more times was detected to be a risk factor of obesity $(\mathrm{P}=0.00)$, and that skipping main meal once, twice, or more per week was also another risk factor of obesity $(\mathrm{P}=$ 0.02) (Table 2). These findings are supported by previous studies as they document that skipping breakfast is positively related to overweight/obesity since those who do not eat early in the morning may feel hungry later and consume higher calories during office time and evening hours than those who eat consistently throughout a day (10). Another study found out that skipping breakfast was correlated with obesity since skipping breakfast resulted in decreasing physical activity and spent calories, consequently leading to obesity development (14). A study in Egypt showed that $94.2 \%$ of women skipped their main meal three or more times per week and only $5.6 \%$ of women skipped their main meal once or twice per week. The former case was statistically correlated with obesity $(\mathrm{P}=0.00)$ (10). A majority of the participants (89.4\%) shared their homemade food with their family members three times almost regularly. On the other hand, few women (10.6\%) had outside meal as a variable statistically related to obesity (P $<.05$ ). The results might be occurred due to those women eaten homemade food, they cook varieties items of high rich food with spice, less intake of vegetables and eat more followed that they became getting more BMI (8).

The present study found that the obese participants consumed snacks more frequently than those with preobese and normal BMI. The term "snack" refers to all fried foods or any fast food items taken at workplace or at 


\begin{tabular}{|c|c|c|c|c|}
\hline \multirow{2}{*}{ Variables/Frequency of Consumption Per Week } & \multicolumn{2}{|c|}{ BMI, No. (\%) } & \multirow{2}{*}{$\chi^{2}$} & \multirow{2}{*}{ P Value } \\
\hline & $<25.0$ & $\geq \mathbf{2 5 . 0}$ & & \\
\hline Skipping breakfast & & & 12.5 & 0.00 \\
\hline Never or rarely & $34(59.6)$ & $23(40.4)$ & & \\
\hline 3 or more times & $56(33.1)$ & $113(66.9)$ & & \\
\hline Skipping main meal & & & 5.15 & 0.02 \\
\hline Never & $65(45.5)$ & $78(54.5)$ & & \\
\hline once, twice or more & $25(30.1)$ & $58(69.9)$ & & \\
\hline Eating meat & & & 0.117 & 0.73 \\
\hline Never or rarely & $22(37.9)$ & $36(62.1)$ & & \\
\hline 3 or more days & $68(40.5)$ & $100(59.5)$ & & \\
\hline Eating eggs & & & 0.279 & 0.58 \\
\hline Never or rarely & $17(43.6)$ & $22(56.4)$ & & \\
\hline 3 or more days & $73(39.0)$ & $114(61.0)$ & & \\
\hline Eating fruits & & & 0.637 & 0.42 \\
\hline Never or rarely & $24(35.8)$ & $43(64.2)$ & & \\
\hline 3 or more days & $66(41.5)$ & $93(58.5)$ & & \\
\hline Eating fried or fast foods & & & 5.76 & 0.01 \\
\hline Never or rarely & $15(62.5)$ & $75(37.1)$ & & \\
\hline 3 or more times & $09(37.5)$ & $127(62.9)$ & & \\
\hline Ice cream/sweets & & & 1.60 & 0.21 \\
\hline Never or rarely & $57(37.0)$ & $97(63.0)$ & & \\
\hline 3 or more days & $33(45.8)$ & $39(54.2)$ & & \\
\hline Tea/coffee & & & 0.014 & 0.91 \\
\hline Never or rarely & $07(41.2)$ & $10(58.8)$ & & \\
\hline 3 or more days & $83(39.7)$ & $126(60.3)$ & & \\
\hline Using salt/Salty foods & & & 1.90 & 0.17 \\
\hline Never or rarely & $54(43.9)$ & $36(35.0)$ & & \\
\hline 3 or more days & $69(56.1)$ & $67(65.0)$ & & \\
\hline Eating vegetables & & & 1.01 & 0.31 \\
\hline Never or rarely & $12(32.4)$ & $25(67.6)$ & & \\
\hline 3 or more days & $78(41.3)$ & $111(58.7)$ & & \\
\hline Soft drinks & & & 0.295 & 0.59 \\
\hline Never & $43(38.1)$ & $70(61.9)$ & & \\
\hline Once, twice or more & $47(41.6)$ & $66(58.4)$ & & \\
\hline Eating with family & & & 3.84 & 0.04 \\
\hline Never or rarely & $14(58.3)$ & $10(41.7)$ & & \\
\hline 3- 4 times or regularly & $76(37.6)$ & $126(62.4)$ & & \\
\hline Eating outside meals & & & 2.46 & 0.12 \\
\hline Never or rarely & $64(37.0)$ & $109(63.0)$ & & \\
\hline 3 or more days & $26(49.1)$ & $27(50.9)$ & & \\
\hline
\end{tabular}

home. The results of this study showed that a majority of the participants (89.4\%) consumed snacks three or more days per week and almost every day as a regular habit. Increased amount of snacks or processed foods is often thought for increased possibilities of obesity (8). Previous studies have indicated that obese participants were used to take more frequent snacks than the non-obese $(8,10)$. High consumption of fried and fatty foods, without be- ing health-conscious and doing physical exercise is a major factor contributing to obesity among working women in Bangladesh. The participants those who did not take breakfast and main meal regularly, they might eat more processed foods or fried foods during office time. On the other hand, those participants, who have breakfast and main meal regularly using homemade foods, cook more tasty foods, eat more food, and get obese, suggesting the 
Table 4. Relationship Between Physical Activity and Sedentary Behavior with Obesity in Adult Working Women $(\mathrm{N}=226)$

\begin{tabular}{|c|c|c|c|}
\hline Variables/Duration & Mean \pm SD & $t$-test/F & PValue \\
\hline \multicolumn{4}{|c|}{ Physical Activity } \\
\hline Exercise & & 1.617 & 0.11 \\
\hline Never perform & $26.39 \pm 3.37$ & & \\
\hline$\leq 30$ minutes & $24.72 \pm 2.70$ & & \\
\hline House work & & 4.101 & 0.02 \\
\hline Never & $27.48 \pm 2.97$ & & \\
\hline Low activity & $27.67 \pm 2.93$ & & \\
\hline High activity & $26.00 \pm 3.40$ & & \\
\hline Cycling & & 0.013 & 0.91 \\
\hline Never & $26.31 \pm 3.36$ & & \\
\hline$<30$ minutes & $26.53 \pm 3.56$ & & \\
\hline Swimming & & 1.181 & 0.24 \\
\hline Never & $26.33 \pm 3.35$ & & \\
\hline$<30$ minutes & $22.35 \pm 0.00$ & & \\
\hline Walking to office & & 2.149 & 0.03 \\
\hline Never & $26.73 \pm 3.41$ & & \\
\hline$<30$ minutes & $25.77 \pm 3.22$ & & \\
\hline \multicolumn{4}{|c|}{ Sedentary Behavior } \\
\hline Watching TV & & 0.029 & 0.97 \\
\hline Never & $26.41 \pm 3.67$ & & \\
\hline$<1$ hour & $26.24 \pm 3.19$ & & \\
\hline$>1$ hour & $26.32 \pm 3.37$ & & \\
\hline Reading & & 1.469 & 0.23 \\
\hline Never & $26.83 \pm 3.90$ & & \\
\hline$<1$ hour & $26.28 \pm 3.41$ & & \\
\hline$>1$ hour & $25.96 \pm 2.87$ & & \\
\hline Using computer & & -0.546 & 0.59 \\
\hline Never used & $26.16 \pm 3.40$ & & \\
\hline Used & $26.41 \pm 3.34$ & & \\
\hline Using social media & & 1.661 & 0.19 \\
\hline Never & $26.83 \pm 3.07$ & & \\
\hline$<1$ hour & $26.47 \pm 3.28$ & & \\
\hline$>1$ hour & $25.79 \pm 3.58$ & & \\
\hline
\end{tabular}

unhealthy dietary habits of the respondents.

Regarding physical activity in this study, about $95 \%$ of the respondents never did regular exercises to spend their calories; hence, physical inactivity was found as the other risk factor of obesity. Similar findings are obtained from a systematic review in which higher physical inactivity among South-Asian women was concerned (15). Tradition- ally, the South-Asian women think taking care of household work activities, supporting extended family members, and along with their job may limit their time to engage in physical activity. A qualitative study conducted among South-Asians living in the United Kingdom concluded that understanding external motivators and social context of the participants' lives is highly crucial in developing successful physical activity interventions (15).

In this study, the participants consumed higher calories through improper dietary patterns however, expended lower amount of calories. The women are unaware of their health status; they should take proper health education measures related to healthy lifestyles, including changing food options, having physical activity, and eliminating sedentary lifestyles reasonably in order to reduce the prevalence of obesity among adult working women $(8$, 9).

Cross-sectional study design, relatively smaller sample size, and examining women in just one urban setting would hinder the generalization of the study findings. As another limitation of this study, the samples were selected using convenient sampling method. Moreover, the other intervening variables such as heart diseases, diabetes, osteoarthritis, dyslipidemia, hypertension, and medications were not addressed in this study. Future studies with larger sample size should be conducted to provide a real picture of this issue and to improve the situation.

\subsection{Conclusions}

According to the findings, high rates of overweight and obesity in Dhaka among adult working women were observed. Married women with older age, working in a bank with higher income, and less physical exercise were significantly more probable to suffer from obesity. The preventive strategies are needed to prevent further increase in the prevalence of overweight and obesity. The findings of this study can provide the data required for monitoring the effectiveness of national programs to prevent and control obesity in Bangladesh, especially among women. Additionally, suitable healthcare strategies are needed to change the unhealthy habits, to minimize the increasing risks of obesity, and to reduce the economic and health burden imposed on adult population. Further studies are recommended to assess the health consequences of the obesity in this group of women and to design lifestyle modification programs to reduce the increasing rate of obesity among women.

\section{Footnotes}

Authors' Contribution: Concept development: all of the authors; data acquisition: Khadija Begum; manuscript 
preparation: Khadija Begum; critical review of the manuscript: all of the authors; final approval: all of the authors

Conflict of Interests: Authors declared no conflict of interest.

Ethical Approval: Official institutional approval was received from the Institutional Review Board of Bangabandhu Sheikh Mujib Medical University and National Institute of Advanced Nursing Education and Research (NIANER), Dhaka, Bangladesh (NIANER/2017-06). Further permission was also taken from two research organizations (Mugda Medical College Hospital and Sonali Bank Ltd.) by a written order.

Funding/Support: It was a self-funded study.

Informed Consent: Informed written consent was taken from the respondents after describing the study objectives, methods, risks, and benefits. Confidentiality of the information and no unauthorized access to data were ensured.

\section{References}

1. Shafique S, Akhter N, Stallkamp G, de Pee S, Panagides D, Bloem MW. Trends of under- and overweight among rural and urban poor women indicate the double burden of malnutrition in Bangladesh. Int J Epidemiol. 2007;36(2):449-57. doi: 10.1093/ije/dyl306. [PubMed: 17242024].

2. WHO. Obesity and overweight. Geneva, Switzerland: World Health Organization; 2018, [cited June 24, 2019]. Available from: https://www. who.int/news-room/fact-sheets/detail/obesity-and-overweight.

3. Sidik SM, Rampal L. The prevalence and factors associated with obesity among adult women in Selangor, Malaysia. Asia Pac Fam Med. 2009;8(1):2. doi: 10.1186/1447-056X-8-2. [PubMed: 19358728]. [PubMed Central: PMC2674032].

4. Bishwajit G. Household wealth status and overweight and obesity among adult women in Bangladesh and Nepal. Obes Sci Pract. 2017;3(2):185-92. doi: 10.1002/osp4.103. [PubMed: 28706731]. [PubMed Central: PMC5478806].
5. Biswas T, Garnett SP, Pervin S, Rawal LB. The prevalence of underweight, overweight and obesity in Bangladeshi adults: Data from a national survey. PLoS One. 2017;12(5). e0177395. doi: 10.1371/journal.pone.0177395. [PubMed: 28510585]. [PubMed Central: PMC5433717].

6. Chan RS, Woo J. Prevention of overweight and obesity: How effective is the current public health approach. Int J Environ Res Public Health. 2010;7(3):765-83. doi: 10.3390/ijerph7030765. [PubMed: 20617002]. [PubMed Central: PMC2872299].

7. Ball K, Abbott G, Cleland V, Timperio A, Thornton L, Mishra G, et al. Resilience to obesity among socioeconomically disadvantaged women: The READI study. Int J Obes (Lond). 2012;36(6):855-65. doi: 10.1038/ijo.2011.183. [PubMed: 21931326].

8. Popkin BM, Adair LS, Ng SW. Global nutrition transition and the pandemic of obesity in developing countries. Nutr Rev.2012;70(1):3-21. doi: 10.1111/j.1753-4887.2011.00456.x. [PubMed: 22221213]. [PubMed Central: PMC3257829].

9. Cecchini M, Sassi F, Lauer JA, Lee YY, Guajardo-Barron V, Chisholm D. Tackling of unhealthy diets, physical inactivity, and obesity: Health effects and cost-effectiveness. Lancet. 2010;376(9754):1775-84. doi:10.1016/S0140-6736(10)61514-0. [PubMed: 21074255].

10. Hassan NE, Wahba SA, El-Masry SA, Elhamid ER, Boseila SA, Ahmed $\mathrm{NH}$, et al. Eating habits and lifestyles among a sample of obese working Egyptian women. Open Access Maced J Med Sci. 2015;3(1):12-7. doi: 10.3889/oamjms.2015.005. [PubMed: 27275190]. [PubMed Central: PMC4877769].

11. Alebshehy R, Shuaib NM, Mbako JD. Determinant analysis of obesity among adult females in Egypt. Egypt J Hosp Med. 2016;65:662-9. doi: $10.12816 / 0033779$.

12. Rengma MS, Sen J, Mondal N. Socio-economic, demographic and lifestyle determinants of overweight and obesity among adults of Northeast India. Ethiop J Health Sci. 2015;25(3):199-208. doi: 10.4314/ejhs.v25i3.2. [PubMed: 26633922]. [PubMed Central: PMC4650874].

13. Jayawardena R, Byrne NM, Soares MJ, Katulanda P, Hills AP. Prevalence, trends and associated socio-economic factors of obesity in South Asia. Obes Facts. 2013;6(5):405-14. doi: 10.1159/000355598. [PubMed: 24107686]. [PubMed Central: PMC5644757].

14. Watanabe Y, Saito I, Henmi I, Yoshimura K, Maruyama K, Yamauchi $\mathrm{K}$, et al. Skipping breakfast is correlated with obesity. J Rural Med. 2014;9(2):51-8. doi: 10.2185/jrm.2887. [PubMed: 25648986]. [PubMed Central: PMC4310153].

15. Ranasinghe CD, Ranasinghe P, Jayawardena R, Misra A. Physical activity patterns among South-Asian adults: A systematic review. Int J Behav Nutr Phys Act. 2013;10:116. doi: 10.1186/1479-5868-10-116. [PubMed: 24119682]. [PubMed Central: PMC3854453]. 